\title{
Do whole body impedance cardiography estimates of left ventricular structure, volumes and function correlate with the gold standard of cardiac magnetic resonance imaging?
}

\author{
Mariam Narous ${ }^{1,2^{*}}$, Eric Yee ${ }^{1,2}$, Karen Cowan ${ }^{1,2}$, Nowell M Fine ${ }^{1,2}$, Yoko Mikami ${ }^{3,2}$, James A White ${ }^{3,2}$, \\ Derek $V$ Exner ${ }^{1,2}$
}

From 19th Annual SCMR Scientific Sessions

Los Angeles, CA, USA. 27-30 January 2016

\section{Background}

Cardiac magnetic resonance (CMR) is considered a gold standard for assessing left ventricular (LV) structure, volume and function. Impedance cardiography has been purported to provide similar information, including a surrogate measure of LV ejection fraction (EF). We sought to determine whether impedance cardiography estimates correlate with CMR values.

\section{Methods}

Consecutive patients $(\mathrm{n}=204)$ undergoing a standard clinical CMR using either $1.5 \mathrm{~T}$ or $3 \mathrm{~T}$ MRI were enrolled. Whole-body impedance cardiography, using the Non-Invasive Cardiac System (NICaS), was performed within 14 days of the CMR. At least 5 consecutive NICaS measurements, calculated every 20 seconds, were averaged to estimate LV stroke volume (SV), cardiac output (CO) and the surrogate of an LV $\mathrm{EF}<55 \%$ (i.e., Granov Goor Index < 10). Short axis cine imaging was performed in accordance with CMR Society guidelines. CMR and NICaS results were compared using linear regression. Bland-Altman (BA) plots were incrementally used to evaluate individual variability in modality correlation over the range of data observed. The capacity of NICaS to predict a CMR-based LV EF $<55 \%$ was determined via receiver operating characteristic curve (ROC) area under the curve (AUC) analysis.

\section{Results}

The study population included 85 (42\%) women, had a mean age of 55 years and a mean CMR EF of $57 \%$ (range $22 \%$ to $82 \%$ ). A modest, significant, linear correlation was found between NICaS and CMR LV SV ( $\mathrm{r}=$ 0.34; $\mathrm{p}<0.0001$ ) (Figure 1), though there was substantial variability within subjects over the range of values (Figure 2). Similar results were observed between NICaS and CMR CO ( $\mathrm{r}=0.19 ; \mathrm{p}=0.007)$. No significant linear correlation between the NICaS estimate of LV EF and CMR LV EF was observed $(\mathrm{r}=0.13 ; \mathrm{p}=0.07)$. There were $72(35 \%)$ subjects with a CMR EF $<55 \%$. ROC analysis showed an AUC for the NICaS LV EF surrogate of 0.53 for predicting a CMR LV EF $<55 \%$ with a sensitivity of $41 \%$ (95\% CI: $30 \%$ to $53 \%$ ) and specificity of $68 \%$ (95\% CI: $59 \%$ to $76 \%$ ).

\section{Conclusions}

NICaS estimates of LV structure, volume and function were only modestly correlated with CMR values and the capacity of impedance cardiography to predict CMR values was limited $\left(\mathrm{r}^{2}\right.$ for $\mathrm{CO}=4 \%$ and $\mathrm{r}^{2}$ for $\mathrm{SV}=$ $11 \%)$. Further, significant variability within patients was seen. NICaS was not reliable for identifying patients with a reduced LV EF, as evidenced by a low ROC area under the curve, modest sensitivity and poor specificity. These data do not support the use of NICaS impedance cardiography as a surrogate marker of LV structure, volume and function as compared to the gold standard of CMR.

'Libin Cardiovascular Institute of Alberta, Calgary, AB, Canada

Full list of author information is available at the end of the article 


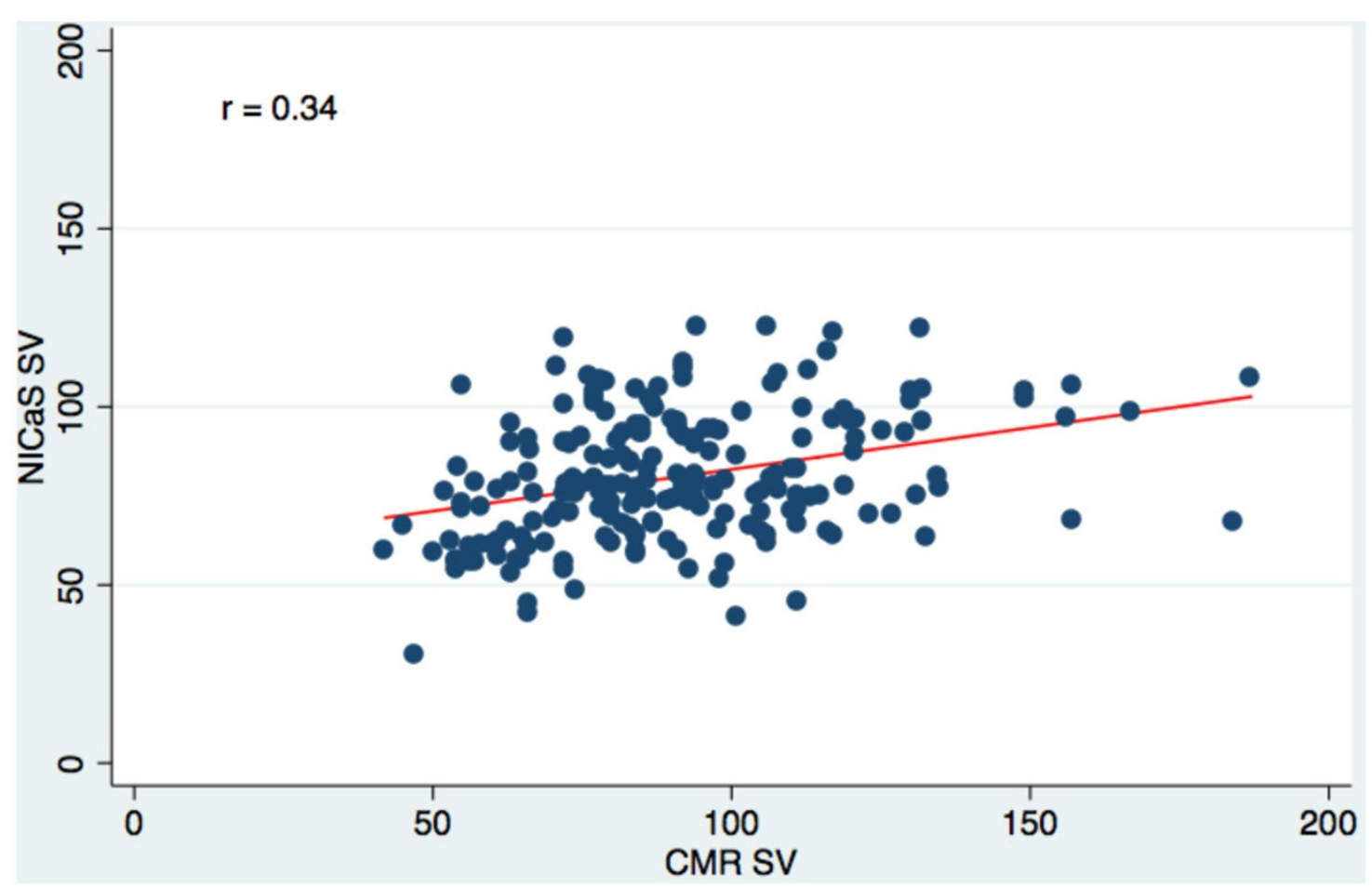

Figure 1 Scatterplot of SV correlation between NICaS and CMR.

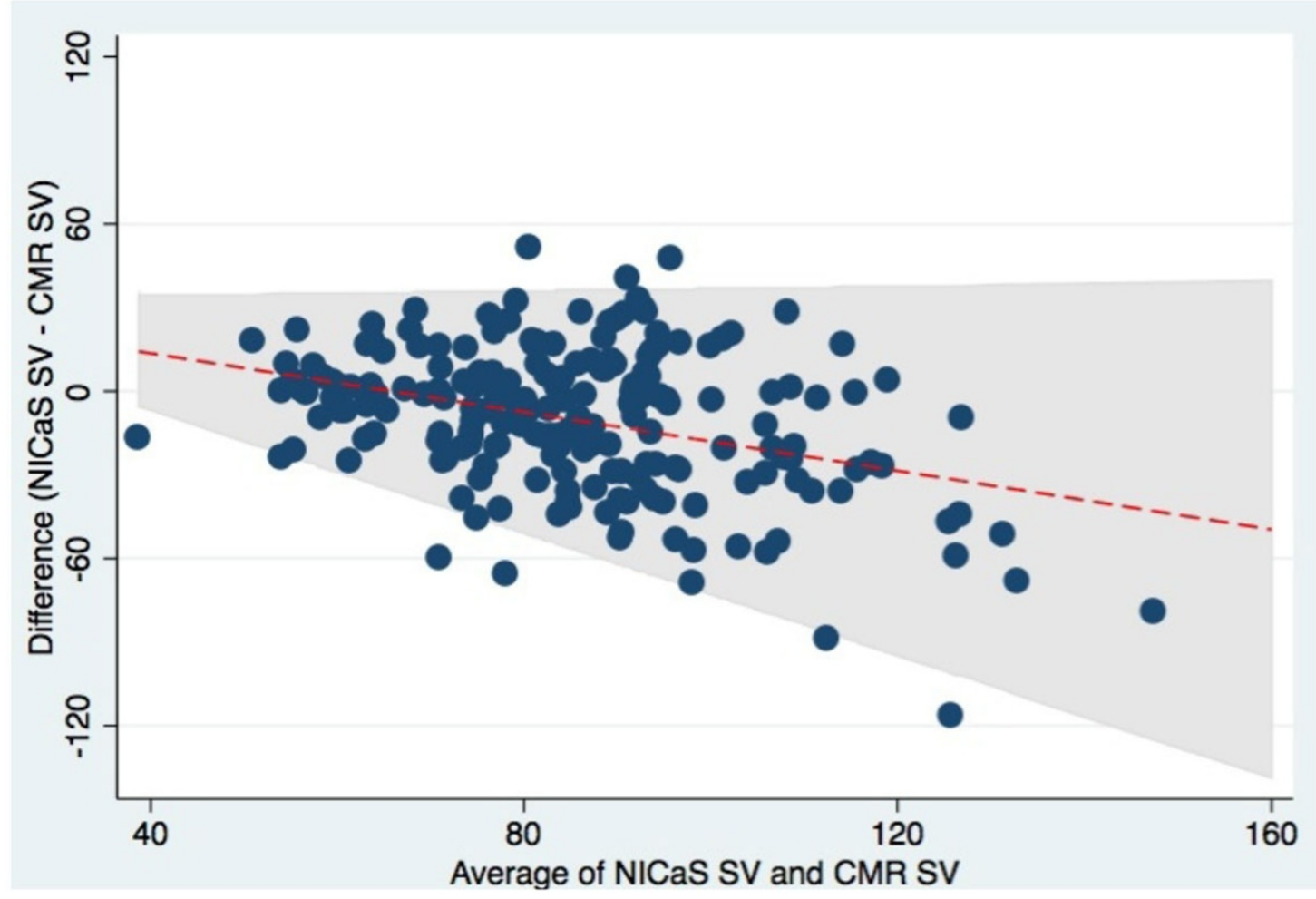

Figure 2 Bland-Altman plot of individual NICaS SV and CMR SD values. 


\section{Authors' details}

${ }^{1}$ Libin Cardiovascular Institute of Alberta, Calgary, AB, Canada. ${ }^{2}$ Cardiac Sciences, University of Calgary, Calgary, AB, Canada. ${ }^{3}$ Stephenson Cardiac Imaging Centre, Libin Cardiovascular Institute of Alberta, University of Calgary, Calgary, AB, Canada.

Published: 27 January 2016

doi:10.1186/1532-429X-18-S1-P194

Cite this article as: Narous et al:: Do whole body impedance cardiography estimates of left ventricular structure, volumes and function correlate with the gold standard of cardiac magnetic resonance imaging? Journal of Cardiovascular Magnetic Resonance 2016 18(Suppl 1):P194.

Submit your next manuscript to BioMed Central and take full advantage of:

- Convenient online submission

- Thorough peer review

- No space constraints or color figure charges

- Immediate publication on acceptance

- Inclusion in PubMed, CAS, Scopus and Google Scholar

- Research which is freely available for redistribution

Submit your manuscript at www.biomedcentral.com/submit
C Biomed Central 